\title{
What Is the Current Development Status of Wearable Device in Industrial 4.0? Using Technology Acceptance Model to Explore the Willingness and Pattern of Usage of the Consumers
}

\author{
Cheng Liu, ${ }^{1}$ Chin-Shyang Shyu, ${ }^{2}$ Tsung-Yu Chou $\mathbb{D},{ }^{3}$ Chao-Chien Chen, ${ }^{4}$ \\ and Chien-Hung $\mathrm{Wu} \mathbb{1}^{5}$ \\ ${ }^{1}$ Department of Healthcare Administration, College of Medical and Health Science, Asia University, Taichung, Taiwan \\ ${ }^{2}$ Department of Recreation and Holistic Wellness, MingDao University, Changhua, Taiwan \\ ${ }^{3}$ Department of Distribution Management, National Chin-Yi University of Technology, Taichung, Taiwan \\ ${ }^{4}$ Department of Leisure and Recreation Management, Asia University, Taichung, Taiwan \\ ${ }^{5}$ Department of Marine Recreation, National Penghu University of Science and Technology, Penghu County, Taiwan
}

Correspondence should be addressed to Chien-Hung Wu; wu1023@gms.npu.edu.tw

Received 15 August 2020; Revised 6 November 2020; Accepted 27 November 2020; Published 18 December 2020

Academic Editor: Kuei-Hu Chang

Copyright (c) 2020 Cheng Liu et al. This is an open access article distributed under the Creative Commons Attribution License, which permits unrestricted use, distribution, and reproduction in any medium, provided the original work is properly cited.

\begin{abstract}
The object of the study is to use the technology acceptance model to explore the willingness and pattern of usage of the consumers. 205 valid questionnaires were collected by using the Google online survey platform. Using IBM SPSS and AMOS Statistics 20.0 software, first background information was analyzed, then CFA was used to analyze the relationship between variables, and SEM was used to verify the rationality of the measurement model. The result discovered that there is a positive effect on perceived usefulness by perceived utility of usage by the users. There is a positive effect on usage intention by perceived utility. There is a positive effect on perceived curiosity by perceived utility. There is a positive effect on usage intention by perceived usefulness, and there is a positive effect on usage willingness by social support for the wearable device users. However, there is no positive effect on usage willingness by perceived curiosity. Conclusion. If the industry can provide consumers with a good experience, it will help enhance consumer attitudes, increase consumer willingness, and continue to enhance consumer curiosity. Simply satisfying consumers' curiosity cannot increase consumer willingness, but social support will affect consumers' willingness to use.
\end{abstract}

\section{Introduction}

The concept of Industrial 4.0 is one of linkage and optimization. With more and more data, broader linkable scope, and faster response speed, there is more variety in the targets that can be optimized. Efficiency and production capacity are also enhanced.

Shuan et al. [1] believed that the key concept of "Industrial 4.0" is linking, using information and communication technology to form Internet of Things (IoT) and Internet of Services (IoS) which link the related machinery, personnel, procedure, and data in a production process together, so each equipment can communicate with each other and has independent supervision, analysis, and determining capabilities that can locate and solve problems to make the production process more agile and flexible in order to respond to the changes in market demand. So communication facility, smart control system, sensors, and embedded terminal system included in a smart network are the core values of Industrial 4.0.

Cheng [2] clearly pointed out that Industrial 4.0 denotes the fourth industrial revolution of smart oriented production. With the coming of the Industrial 4.0 age, humans will construct, based on Cyber-Physical System, an integrated industrial Internet of Things industry that includes smart manufacturing, digitalized factory, Internet of Things, and Internet of Services through information and communication technology to achieve virtual mock technology and 
machine production that reciprocate each other, making smart factory a reality while achieving a close-knit value chain. On the other hand, in Industrial 4.0, the concept of "quantifying the self" has gradually penetrated into people's daily life. Through the help of technology, people begin to record the data of their own body to pursue sports performance or to keep fit. Wearable device is the major object of development in this trend. Swan [3] believes that the advancement of technology has made sensors become ever smaller and the functionality of wireless transmission faster. The prevalence of wearable devices has become more and more popular. The scope of the data a wearable device can record is quite varied, including weight, energy level, emotion, usage time, sleep quality, health, and perceived performance [4]. The observation in 2019 of the information technology research institution, Gartner, pointed out that worldwide end-user spending on wearable devices will total $\$ 52$ billion in 2020-an increase of $27 \%$ from 2019-according to the latest forecast from Gartner, Inc. In 2019, worldwide wearable devices end-user spending is on pace to reach $\$ 41$ billion. End users will spend the most on smartwatches and smart clothing with spending growing $34 \%$ and $52 \%$ in 2020 , respectively.

Smartwatches and ear-worn devices will take the lead in terms of shipments in 2020, with smartwatch shipments forecast to a total of 86 million units and ear-worn wearable shipments reaching 70 million units. From Table 1, the current development status of wearable devices can be observed.

Even though the development of wearable devices has become more popular, however, there are still some issues that deserve attention in its development. The Science \& Technology Policy Research and Information Center, National Applied Research Laboratories [6], already pointed out that, in the short run, even though wearable devices will develop toward the direction of medical care and health industry in the next few years, a balance has to be located between hardware price and service price in order to attract more consumer groups to purchase wearable devices [7], or it will not be just the $\mathrm{X}$ generation who will not make the purchase, and the millenniums and the $Y$ generation will not as well due to lack of attraction. In other words, researching into the usage behavior of wearable devices by consumers has its own practical value. In regard to using technology by the people, as for how to make a reasonable deduction based on the willingness of behavior while such willingness is affected by the attitude, the technology acceptance model based on rational behavior model and theory of planned behavior proposed by Davis et al. [8] is the basis for exploring the topic.

Many tools in human life are designed with the intervention of the concept of Industry 4.0 [7]. The main goals being explored are to optimize the power and energy systems, reduce carbon dioxide emissions [8], or reduce industrial costs through cloud computing [9], optimize human and computer intelligence [10], and increase overall industrial efficiency $[11,12]$. However, the concept of Industry 4.0 is not limited to the industrial sector; more advanced countries are using the manufacturing sector as a base to
TABLE 1: Worldwide wearable devices end-user spending by type, 2018-2021 (millions of dollars).

\begin{tabular}{lcccc}
\hline Device type & 2018 & 2019 & 2020 & 2021 \\
\hline Smartwatch & 12,412 & 17,047 & 22,803 & 27,388 \\
Head-mounted display & 5,354 & 7,183 & 10,609 & 15,501 \\
Ear-worn & 6,780 & 7,885 & 8,716 & 9,927 \\
Sports watch & 3,647 & 4,121 & 4,555 & 4,912 \\
Wristband & 3,405 & 3,194 & 3,115 & 3,055 \\
Smart clothing & 848 & 1,151 & 1,746 & 2,202 \\
Total & 32,446 & 40,581 & 51,545 & 62,985 \\
\hline
\end{tabular}

Source: Gartner [5].

extend product development, sales, and services to provide a coherent industrial sales service [13]. Therefore, any technology that can satisfy the supply and demand of the society by transferring information between machines, offering the nine technologies such as Cloud Technology, Internet of Things, Big Data \& Analytics, Additive Manufacturing, Automation, System Integration, Cyber Security, Augmented Reality, and Simulation to humans [14] and applying them in the service and manufacturing industries without human intervention and within the technical, profitable, ethical, and legal boundaries, is included in the definition of Industry 4.0. And its definition and the application of technology are gradually extended outward $[13,15]$.

Due to the pressure of work and life, people gradually lose the opportunity to exercise. The sports industry has seized the opportunity to develop sports bracelets, attempting to enter the human sports and health market with products featuring the convenience of technology, the ability to exercise anytime, anywhere, and the concept of self-monitoring $[4,5]$. However, consumers have different experiences with technology products, and the differences can be explored by the technology acceptance model [16-19]. Therefore, it is suggested that using the technology acceptance model theory to explore people's perceptions of technology use can help to understand the future development trend of related technology industries.

\section{Overview of the Technology Acceptance Model}

Davis [9] pointed out that the main purpose of the technology acceptance model is in providing a normalized model that explores the willingness of a person to use information technology to track the relationship between external variables, user perception, attitude, and intention and then further explain and predict effectively the technology usage behavior of the user. In order to measure the acceptance rate of new technology by the user even more precisely, Davis constructed a scale on perceived utility and perceived utility in which the perceived utility is where the user believes that using a certain system can increase a certain level of performance while utility is where the user believes that using a certain system will feel a certain degree of difficulty. From the view of the technology acceptance model, wearable device is one of the tools for people to quantify themselves, in terms of interface or the transmission of data being easily 
accessible or used about which are what the consumers care. Under the circumstance of the wearable device being easy to use, the data or information acquired by the consumer is what makes the consumer feel that the wearable device is useful equipment [10]. The research of Yi and Luo [11] points out perceived utility will positively affect perceived utility; therefore, it follows that the perceived utility will have a positive impact. On the other hand, a wearable device that is easy to use without complicated design should theoretically increase the willingness in a consumer to use. The research of Shu and Jun [12] also points out that perceived utility has a positive effect on willingness to use; therefore, this research deduces that perceived utility has a positive effect on willingness to use by the user. On another side, the perceived utility having an effect on curiosity has also been proven. The research result of Cheng et al. [13] shows that perceived utility has an effect on curiosity; therefore, this research deduces that there is a positive effect on curiosity by perceived utility of a wearable device. In addition to the ease of usage of a wearable device, the information or data collected by the wearable device makes the users feel that it is helpful. The research of Kuo Yu Yuen points out that perceived utility has a positive effect on willingness to use; therefore, this research deduces that perceived utility has a positive effect on willingness to use by the user. Most of the time, people use a new product or one that can elevate selfsports performance out of need or curiosity followed by willingness to use. The research of Cheng et al. [13] points out that curiosity has a positive effect on the willingness to use; therefore, this research deduces that curiosity on the wearable device has a positive effect on the willingness to use [14]. When people decide to do something or play the help and support that parents, relatives, and friends of an important other can give spiritually or materialistically, the decision may increase the willingness to use in that person [15]. The research of Chi and Ling [16] shows that social support has a positive effect on the willingness to use; therefore, this research deduces that if the wearable device user may receive even more social support, the willingness to use will be much higher [17]. The positive effect on usage behavior by willingness to use is also proven by the research result of Long [18]; therefore, this research deduces that the willingness to use by a wearable device user has a positive effect on usage behavior [19].

Overall, exercise can promote physical and mental health. The sports wearable device that combines the cloud technology in Industrial 4.0 can facilitate people to manage their individual health condition more effectively and speedily due to the convenience and increase mobility. However, the impact of lack of attractiveness of the hardware and service [6] will result in the inability of the device being not able to attract the people. The technology acceptance model can explain and predict the usage behavior of technology by users from the relationship between external variables, user perception, attitude, and intention [9], which is helpful in obtaining the willingness to use by the consumer on the wearable device and the model. Therefore, this research will provide recommendations on the future development of the sports wearable device-related industry by the analysis and exploration of consumers' willingness to use and usage model to understand the current development status of the sports wearable devices combining cloud technology.

\section{Methods}

3.1. Structural Model. Although sports wearable devices may increase convenience and mobility and manage individual health condition even more effectively by combining cloud technology, however, the impact of lack of attractiveness of the hardware and service [6] will result in the inability of the device being not able to attract the people. The research has discovered that using the technology acceptance model theory structure to explore consumer's usage willingness and model $[9,11-13,18,20-23]$ can further analyze the feel and experience of consumers in the cloud technology products in Industrial 4.0 and locate the difficulty and space for improvement in related products and industry development. Therefore, the research uses sports wearable device as the topic to analyze the consumer's usage willingness and model for wearable devices and deduces indirectly the current status of development of sports wearable devices in order to provide sports wearable devicerelated industry and product recommendations for future development. The research structure is shown in Figure 1.

3.2. Research Hypothesis. As illustrated in the research structure, the hypotheses of the research are as follows:

H1: perceived utility has a positive impact on perceived
utility

$\mathrm{H} 2$ : perceived utility has a positive impact on usage willingness

H3: perceived utility has a positive impact on perceived curiosity

H4: perceived utility has a positive impact on usage willingness

H5: perceived curiosity has a positive impact on usage willingness

H6: social support has a positive impact on usage willingness

H7: usage willingness has a positive impact on usage behavior

3.3. Research Subjects. The research adopted a questionnaire method using sports wearable device users in Taiwan as research subjects to explore the usage willingness and behavior model of users on sports wearable devices in Taiwan. Using the Google online survey platform to conduct questionnaire collection which started from May 6 to June 30,2020 , for a total of 205 valid questionnaires. Finally, SPSS 20.0 statistical software was used to encode the data and descriptive analysis was used to analyze sample background information. SEM is suitable for verifying the statistical analysis of a hypothetical model. Therefore, the researcher must first develop an appropriate research model structure based on the theory or literature discussion process and then 


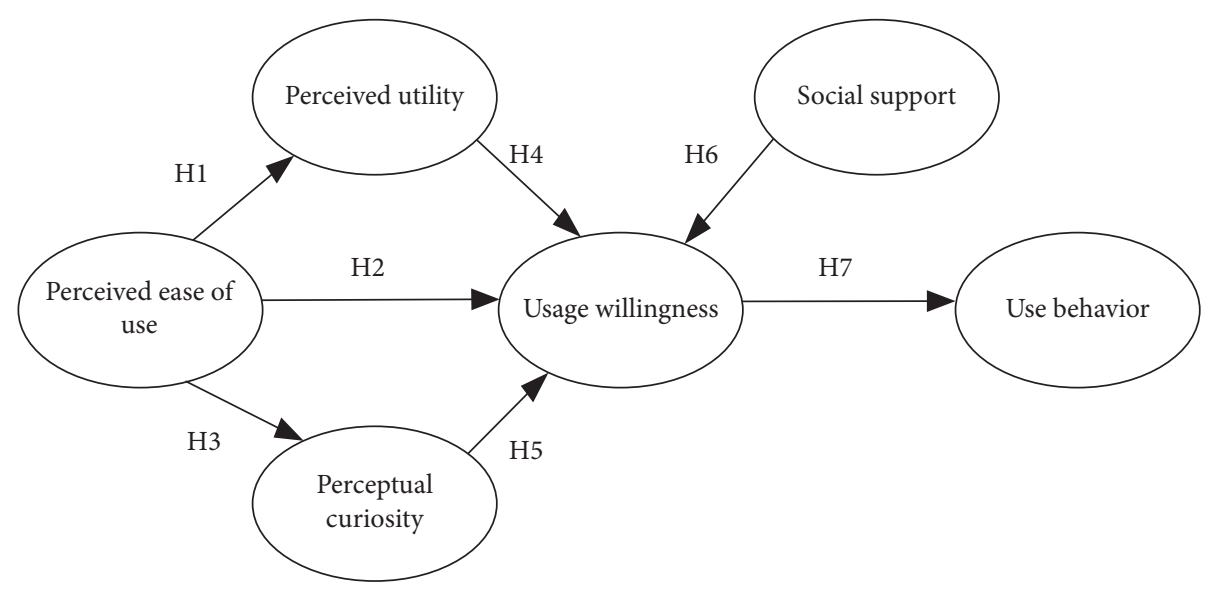

FIGURE 1: The research structure.

use SEM to verify and analyze the model. The structure contains two subsystems, namely, the "measurement model" and the "structural model". The measurement model defines the relationship between the measured variable and the latent variable, while the structural model defines the relationship between the potential variables, where the measured variable is the basic element for SEM process analysis and calculation, also known as observed variables, and the potential variables are those estimated from measured variables [24]. So next, AMOS 20.0 software was used to analyze the relationship between variables and verify the rationality of the research model.

3.4. Study Procedure and Instruments. The objective of the study is to understand the usage willingness and behavior model of the users on sports wearable devices in Taiwan. Questionnaire investigation was adopted with the theory structure of the technology acceptance model. Related literature studies were referenced $[9,11-13,18,25-29]$ to compile a research questionnaire for analysis as illustrated in Table 2 . The content of the questionnaire can be divided into 6 parts of background information, usage behavior and model, easy to use, usefulness, curiosity, usage willingness, and social support. For background information and usage behavior and model, refer to Shu and Jun [12] and Long [18]. For perceived utility and usefulness, refer to $[9,30,31] .13$ questions were compiled. For curiosity, see [13]. 4 questions were compiled. For usage willingness, refer to [32]. A total of 5 questions were compiled. For social support, refer to [33] for a total of 7 questions for a sum of 26 questions in total.

The 5-point Likert-type scale was used; completely agree, agree, nor agree, nor disagree, and completely disagree are on a scale of $1-5$ points. The sociodemographic variables are as follows. We first understand the gender of the sample: male or female; age: under 20, 21-30, 31-40, 41-50, 51-60, and over 60; place of residence: the north, the central region, the south, the east, and off-shore islands. Education: elementary school, junior high school, high school, college/ university, and graduate school and above. Usage behavior and patterns include the following: behavior: personal activity, peer group activity, family activity, occupation activity, medical care or others (complying with the project); model: daily life, work, leisure sports, travel, and other needs (medical care and health requirement).

3.5. Information Processing and Analysis. After collecting the questionnaires and deleting the invalid questionnaires, the study used SPSS 20.0 to establish a document and conduct statistical verification and analysis on the questionnaire. Next, AMOS 20.0 is used to conduct the analysis on the relationship between variables and verification of the plausibility of the research model, as shown in Figures 2-5.

\section{Research Result}

4.1. Sample Descriptive Statistics. The research is using sports wearable device users in Taiwan as research subjects and samples. The status of compiled information analysis is as follows: from Table 3, there are 205 valid samples. In terms of gender, there are 131 males, $63.9 \%$ of the valid sample, and there are 74 females, $36.1 \%$. In terms of age, the most are under 20 (inclusive) years old with 100 people at $48.8 \%$ of the valid sample, 50 people are $21-30$ years old at $24.4 \%$, and 3 people are over 61 years of age, the least at $1.5 \%$, indicating that sports wearable device users in Taiwan as research subjects are mostly under 20 (inclusive) years old. In terms of place of residence, the most are living in the middle region with 150 people at $73.2 \%, 41$ people living in the north are in the second place at $20.0 \%$, and 2 people are in the east, the least at $1.0 \%$. As for education level, 188 college/university students are the most at $91.7 \%$ of the valid sample, 8 high school students are in the second place at 3.9\%, and 2 students under junior high school are the least at $1.0 \%$.

Research inference: although Taiwanese people have a thriving national sports atmosphere, work or study factors reduce the exercise time. For male external items, most people prefer sports. In addition, the majority of users are males under the age of 20 , students, etc.

4.2. Offending Estimate. Before undertaking the checking on overall goodness of fit, there needs to be a check on offending estimate; therefore, this study is in compliance with no 
TABLE 2: Usage willingness and model questionnaire for sports wearable device consumers.

\begin{tabular}{|c|c|c|}
\hline $\begin{array}{l}\text { Main part of the } \\
\text { questionnaire }\end{array}$ & Content & $\begin{array}{l}\text { Question } \\
\text { number }\end{array}$ \\
\hline \multirow{3}{*}{$\begin{array}{l}\text { Background information } \\
\text { Usage behavior and } \\
\text { patterns }\end{array}$} & Gender, age, place of residence, education level & $1-4$ \\
\hline & Usage behavior, usage pattern, time length of wearing & $5-7$ \\
\hline & $\begin{array}{c}\text { C1: the convenience of obtaining analysis information from the sports bracelet } \\
\text { C2: able to use the sports bracelet for analysis through linking cell phone with the sports } \\
\text { bracelet software } \\
\text { C3: simple and easy to understand the analysis information of the sports bracelet } \\
\text { C4: access to collecting and interpreting sports bracelet analysis information is convenient } \\
\text { C5: no interference (artificial, speed of software computing, advertisement) when receiving } \\
\text { sports bracelet analysis data }\end{array}$ & $8-11$ \\
\hline \multirow[t]{3}{*}{$\begin{array}{l}\text { Ease of usage and } \\
\text { usefulness }\end{array}$} & $\begin{array}{c}\text { C6: ability to obtain professional analysis data and recommendations when using sports } \\
\text { bracelet to exercise }\end{array}$ & \\
\hline & $\begin{array}{c}\text { D1: using sports bracelet when exercising reduces my lack of exercise problem } \\
\text { D2: using sports bracelet when exercising can enhance the result of my exercise } \\
\text { D3: using sports bracelet can increase my determination to exercise }\end{array}$ & \\
\hline & $\begin{array}{l}\text { D4: using sports bracelet can increase my frequency of doing exercise } \\
\text { D5: using sports bracelet can increase my work satisfaction } \\
\text { D6: using sports bracelet can increase my quality of life } \\
\text { D7: using sports bracelet can reduce the stress from my work and life }\end{array}$ & $12-15$ \\
\hline Curiosity & $\begin{array}{l}\text { EE1: using sports bracelet can inspire the curiosity in me as to how to solve a problem } \\
\text { EE2: using sports bracelet can improve the result of my work/learning } \\
\text { EE3: using sports bracelet can lead me to explore the condition of my health } \\
\text { EE4: using sports bracelet can awaken my imagination for solving my problems }\end{array}$ & $16-18$ \\
\hline
\end{tabular}

G1: when a personal problem arises to affect my sports performance, I will be willing to use the sports bracelet

G2: when there is a problem in my physical and mental health, I will be willing to use the sports bracelet

Usage willingness G3: I am willing to continue using the sports bracelet until there is an improvement in my physical and mental health

G4: I am willing to continue using the sports bracelet until there is an improvement in my sports performance

G5 I am willing to recommend using sports bracelet to other colleagues or friends and family.

F1: when my health condition becomes worse, my colleagues/classmates are willing to support me in using the sports bracelet to improve my health

F2: when my health condition becomes worse, my friends and family are willing to support me in using the sports bracelet to improve my health

F3: when my health condition becomes worse, my colleagues/classmates are willing to support me in using the sports bracelet to improve the result of exercise

Social support $\quad$ F4: when my health condition becomes worse, my friends and family are willing to support me in using the sports bracelet to improve the result of exercise

F5: in life around me, wearing sports bracelet to improve life and health is being supported and encouraged

F6: in life around me, colleagues/classmates play the role of encouraging me to use the sports bracelet

F7: in life around me, friends and family play the role of encouraging me to use the sports bracelet

offending estimate [29-35]. Offending estimates are used to check whether the estimated coefficients are within an acceptable range before assessing model fitness [36]. Offending estimates exists when the estimate coefficients show (1) negative error variance, (2) insignificant error variance, (3) standardized regression coefficients that are above or too close to 1 (with a threshold of .95), and (4) too large a standard error [37, 38].

From Tables $4-7$, the variances in the research are 0.02 to 0.05 and the standardized coefficient is 0.72 to 0.93 , not over the standardized value of 0.95 , and can thus be used to conduct goodness-of-fit check with the overall model of the study.

4.3. Measurement Mode Analysis. The questionnaire of the research employed confirmatory factor analysis to verify reliability and validity and conducted item modification according to modification indices (MI) [39]. So the research deleted items with too high MI values in C5, C6, D3, D5, and D7 of the perceived utility and perceived utility model scale; 


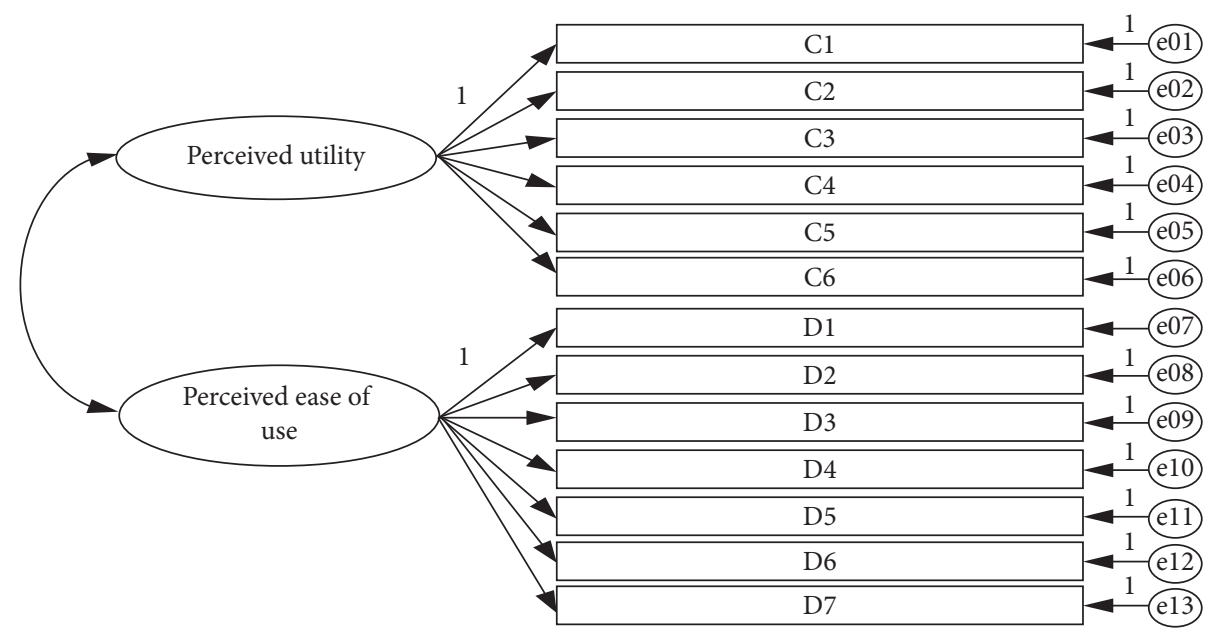

FIGURE 2: Perceived utility and perceived ease of use model using confirmatory factor analysis structure.

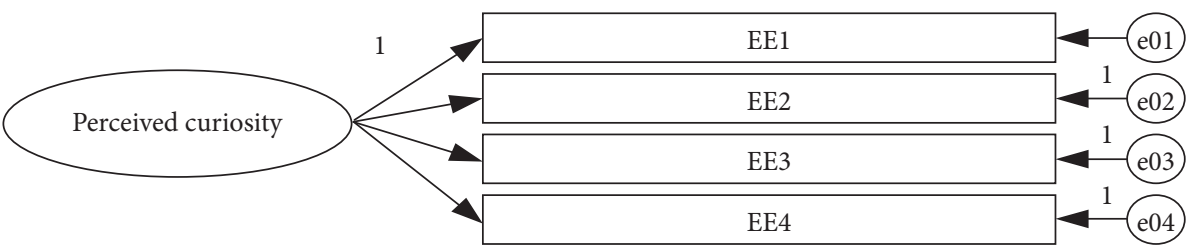

FIGURE 3: Perceived curiosity model using confirmatory factor analysis structure.

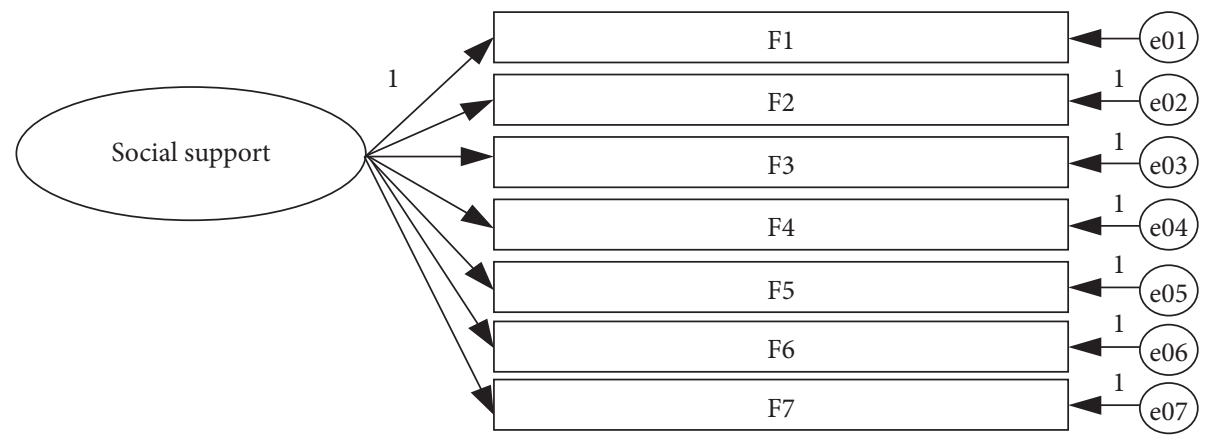

FIgURE 4: Social support model using confirmatory factor analysis structure.

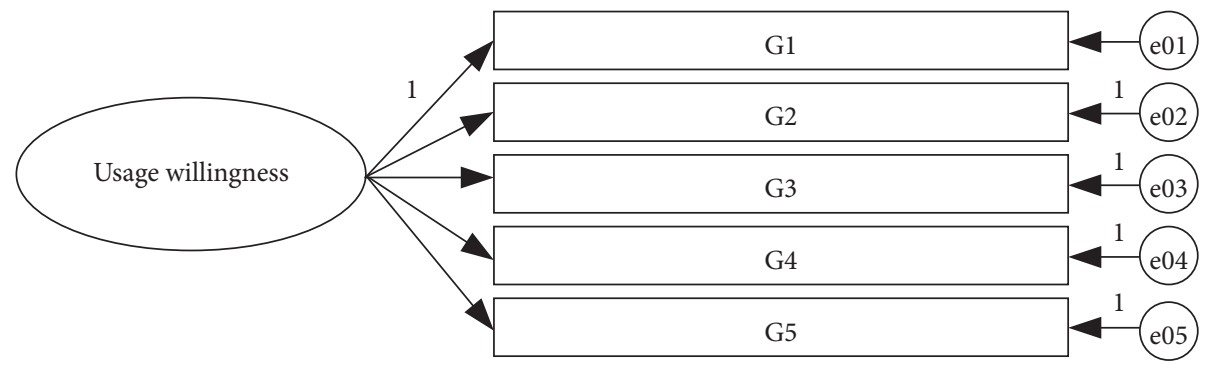

Figure 5: Usage willingness model using confirmatory factor analysis structure.

EE4 of perceived curiosity model scale, F1, F2, and F7 of social support model scale, and G4 of the usage willingness model scale. The rest are within the range and are kept.
4.3.1. Verification of Convergent Validity. Bagozzi and Yi [33] believe that convergent validity can be derived from the composite reliability (CR) and average variance extracted 
TABLE 3: Structure of the sample of the subjects.

\begin{tabular}{lccc}
\hline Variable & Category & Frequency & $\%$ \\
\hline \multirow{2}{*}{ Gender } & Male & 131 & 63.9 \\
& Female & 74 & 36.1 \\
\hline \multirow{4}{*}{ Age } & Under 20 (inclusive) & 100 & 48.8 \\
& $21-30$ & 50 & 24.4 \\
& $31-40$ & 23 & 11.2 \\
& $41-50$ & 12 & 5.9 \\
Place of & $51-60$ & 17 & 8.3 \\
residence & Above 61 & 3 & 1.5 \\
& The north & 41 & 20.0 \\
& Middle region & 150 & 73.2 \\
& The south & 12 & 5.9 \\
Education level & The east & 2 & 1.0 \\
& Under junior high school & 2 & 1.0 \\
& High (vocational) school & 8 & 3.9 \\
& College/university & 188 & 91.7 \\
& Above graduate school & 7 & 3.4 \\
\hline
\end{tabular}

TABle 4: Perceived utility and perceived utility scale offending estimate check table.

\begin{tabular}{lcc}
\hline Item code & $\begin{array}{c}\text { Standardized regression } \\
\text { coefficient }\end{array}$ & $\begin{array}{c}\text { Deviation } \\
\text { variance }\end{array}$ \\
\hline C1 & 0.90 & 0.02 \\
C2 & 0.91 & 0.02 \\
C3 & 0.90 & 0.02 \\
C4 & 0.87 & 0.02 \\
C5 & 0.79 & 0.04 \\
C6 & 0.82 & 0.03 \\
D1 & 0.77 & 0.04 \\
D2 & 0.89 & 0.02 \\
D3 & 0.91 & 0.02 \\
D4 & 0.93 & 0.02 \\
D5 & 0.85 & 0.03 \\
D6 & 0.88 & 0.03 \\
D7 & 0.81 & 0.04 \\
\hline
\end{tabular}

Table 5: Perceived curiosity scale offending estimate check table.

\begin{tabular}{lcc}
\hline Item code & $\begin{array}{c}\text { Standardized regression } \\
\text { coefficient }\end{array}$ & $\begin{array}{c}\text { Deviation } \\
\text { variance }\end{array}$ \\
\hline EE1 & 0.83 & 0.05 \\
EE2 & 0.89 & 0.03 \\
EE3 & 0.90 & 0.03 \\
EE4 & 0.81 & 0.04 \\
\hline
\end{tabular}

TABLE 6: Social support scale offending estimate check table.

\begin{tabular}{lcc}
\hline Item code & $\begin{array}{c}\text { Standardized regression } \\
\text { coefficient }\end{array}$ & $\begin{array}{c}\text { Deviation } \\
\text { variance }\end{array}$ \\
\hline F1 & 0.73 & 0.04 \\
F2 & 0.89 & 0.02 \\
F3 & 0.91 & 0.02 \\
F4 & 0.92 & 0.02 \\
F5 & 0.91 & 0.02 \\
F6 & 0.86 & 0.03 \\
F7 & 0.81 & 0.04 \\
\hline
\end{tabular}

TABLE 7: Usage willingness scale offending estimate check table.

\begin{tabular}{lcc}
\hline Item code & $\begin{array}{c}\text { Standardized regression } \\
\text { coefficient }\end{array}$ & $\begin{array}{c}\text { Deviation } \\
\text { variance }\end{array}$ \\
\hline G1 & 0.72 & 0.05 \\
G2 & 0.93 & 0.02 \\
G3 & 0.93 & 0.02 \\
G4 & 0.90 & 0.02 \\
G5 & 0.90 & 0.02 \\
\hline
\end{tabular}

(AVE) of factor perspective. The recommended CR value should be greater than 0.7 and AVE greater than 0.5 to show that the questionnaire has convergent validity [36]. The study employs factors such as perceived utility, perceived utility, perceived curiosity, usage willingness, social support, and usage behavior to conduct convergent validity verification. All factor loadings are between 0.78 0.94 in which the CR value is between 0.91 0.94 and AVE between 0.77 -0.81, in compliance with the normal range of Bagozzi and Yi [33], Hair et al. [34], and Fornell and Larcker [40]; therefore, this research complies with convergent validity, as shown in Table 8.

4.3.2. Discriminant Validity Verification. Long [41] pointed out that discriminant validity is to verify the existence of correlation and significant difference between two different perspectives. The bootstrap 95\% confidence interval suggested by Torkzadeh et al. [42] was used to check the related coefficient between perspectives. If 1 does not appear, it means it is completely correlated and has discriminant validity. From Table 9, the bootstrap 95\% confidence intervals are all less than 1, indicating that the research complies with discriminant validity $[41,43]$, as shown in Table 9.

The present study used the bootstrap method to establish the confidence intervals of Pearson's correlation coefficients between perspectives. If the confidence interval does not contain 1, then the null hypothesis is rejected, i.e., it is perfectly correlated, which means that there is discriminant validity between perspectives [39]. In this study, the bootstrap assessment was repeated 1000 times, and at the 95\% confidence level, it was found that no confidence interval including 1 occurred between perspectives. Therefore, the perspectives of the first-order model in this study show discriminant validity.

4.3.3. Structural Model Analysis. The study refers to the structural model analysis of Hair et al [34]. After considering scholars' views [37, 44-50], eight indicators were selected for the overall model fitness assessment, including the chisquare test $(\chi 2)$, the ratio of chi-square to degrees of freedom $(\chi 2 / \mathrm{df})$, the goodness-of-fit index (GFI), the adjusted goodness-of-fit index (AGFI), root mean square error of approximation (RMSEA), nonnormed fit index NNFI (TLI), incremental fit index (IFI), and the comparative fit indicator (CFI), to illustrate the structural model analysis including the model fitness and the explanatory power of the overall model. Analysis on 6 item indices of $\chi^{2}$ (chi-square), $\chi^{2}$ and 
TABLE 8: Perceived utility and perceived utility, perceived curiosity, social support model using confirmatory analysis.

\begin{tabular}{|c|c|c|c|c|c|c|c|c|c|}
\hline Perspective & Index & Standardized factor loading & Nonstandardized factor loading & SE & CR (t-value) & $P$ & SMC & CR. & AVE \\
\hline \multirow{4}{*}{ Perceived utility } & PC1 & 0.90 & 1.00 & & & & 0.81 & \multirow{4}{*}{0.94} & \multirow{4}{*}{0.81} \\
\hline & PC2 & 0.92 & 1.04 & 0.05 & 20.93 & $* * *$ & 0.84 & & \\
\hline & PC3 & 0.91 & 1.01 & 0.05 & 20.39 & $* * *$ & 0.83 & & \\
\hline & PC4 & 0.87 & 0.93 & 0.05 & 17.95 & $* * *$ & 0.75 & & \\
\hline \multirow{4}{*}{ Perceived utility } & PD1 & 0.78 & 1.00 & & & & 0.61 & \multirow{7}{*}{0.91} & \multirow{7}{*}{0.77} \\
\hline & PD2 & 0.92 & 1.18 & 0.08 & 15.12 & $* * *$ & 0.85 & & \\
\hline & PD4 & 0.90 & 1.19 & 0.08 & 14.59 & $* * *$ & 0.81 & & \\
\hline & PD6 & 0.87 & 1.10 & 0.08 & 14.00 & $* * *$ & 0.76 & & \\
\hline \multirow{3}{*}{ Curiosity } & PEE1 & 0.85 & 1.00 & & & & 0.72 & & \\
\hline & PEE2 & 0.87 & 0.90 & 0.06 & 15.48 & $* * *$ & 0.75 & & \\
\hline & PEE3 & 0.92 & 0.94 & 0.06 & 16.30 & $* * *$ & 0.84 & & \\
\hline \multirow{4}{*}{ Social support } & PF3 & 0.91 & 1.00 & & & & 0.83 & \multirow{4}{*}{0.94} & \multirow{4}{*}{0.81} \\
\hline & PF4 & 0.92 & 1.06 & 0.05 & 22.03 & $* * *$ & 0.85 & & \\
\hline & PF5 & 0.94 & 1.03 & 0.04 & 23.05 & $* * *$ & 0.88 & & \\
\hline & PF6 & 0.84 & 0.93 & 0.05 & 17.38 & $* * *$ & 0.71 & & \\
\hline
\end{tabular}

TABLe 9: Perceived utility and perceived utility—bootstrap 95\% confidence interval table of related coefficients.

\begin{tabular}{ccccccc}
\hline \multirow{2}{*}{ Parameter } & Estimate & \multicolumn{2}{c}{ Bias-corrected } & \multicolumn{2}{c}{ Percentile method } \\
& & & Lower boundary & Upper boundary & Lower boundary & Upper boundary \\
\hline Perceived utility $<->$ & Perceived utility & 0.70 & 0.57 & 0.80 & 0.58 & 0.80 \\
\hline
\end{tabular}

degree of freedom ratio, GFI, AGFI, RMSEA, and CFI was conducted to undertake overall model fitness test. For $\chi^{2}$ and its degree of freedom ratio, the smaller the value, the better it is [33]. The ratio after modification in the study is 1.48. For GFI and AGFI values, the closer to 1 , the better it is [33]. The values after modification in the study are 0.96 and 0.94 , respectively. RMSEA value is the best to be between 0.05 and 0.08 [51]. The value after modification in the study is 0.04 . In addition, CFI standard value should be greater than 0.90 . The value after modification in the study is 0.99 . The above are the fit indices of the structural model. RMSEA is also an indicator of fitness, with a larger value indicating a poor fit between the hypothetical model and the data. It has received much attention in recent years and many studies have shown that it performs better than many other indicators [52-56]. If the RMSEA is less than 0.05, then the model has a good fit [57-61], and it is recommended that the RMSEA should be less than or equal to 0.06 [51]; if it is between 0.05 and 0.08 , then the model has a fair fit [62], and if the index exceeds 0.10 , then the model is not a good fit [53]. Although RMSEA is less affected by sample size, it is often overestimated when the sample size is very small [63]. Based on the above description, the results of this analysis show that the overall health index of the study is within an acceptable range, as shown in Table 10.

Analyze and explain according to the path results in Figure 6 and Table 11. From the above research result, it is derived that hypothesis 1 of the research is true in that there is a positive effect on perceived utility by perceived utility of the sports wearable device users (0.73). The research result is consistent with that of $\mathrm{Yi}$ and Luo [11]. The possible reason is that there are many technology products now with
TABLE 10: Overall model fitness analysis.

\begin{tabular}{lccc}
\hline Fit index & $\begin{array}{c}\text { Tolerable } \\
\text { range }\end{array}$ & $\begin{array}{c}\text { Modified } \\
\text { model }\end{array}$ & $\begin{array}{c}\text { Model fit } \\
\text { determination }\end{array}$ \\
\hline$\chi^{2}$ (chi-square) & $\begin{array}{c}\text { The smaller } \\
\text { the better }\end{array}$ & 269.57 & \\
$\chi^{2}$ and degree of & $<3$ & 1.48 & Fit \\
freedom ratio & $>0.80$ & 0.96 & Fit \\
GFI & $>0.80$ & 0.94 & Fit \\
AGFI & $<0.08$ & 0.04 & Fit \\
RMSEA & $>0.90$ & 0.99 & Fit \\
CFI & & &
\end{tabular}

relatively complex functions, yet people normally think that the process of learning a new thing is not that present. So, if, at the time of an interesting wearable device appearing, the use of the device can be convenient and easy, to the user, it will be a useful product and the user will further obtain related exercise data or monitoring function from using the sports wearable device when exercising each time.

Hypothesis 2 is true in that there is a positive effect on usage intention by perceived utility (0.24). The research result is consistent with that of Shu and Jun [12]. We conjecture that the possible reason is that as technology becomes more humanized and easy to use in that there are not too many obstacles for the user, the willingness to use the equipment will be increased.

Hypothesis 3 of the research is true in that there is a positive effect on perceived curiosity by perceived utility (0.64). The research result is the same as that of Cheng et al. [13]. The possible reason is that when wearable device is an 


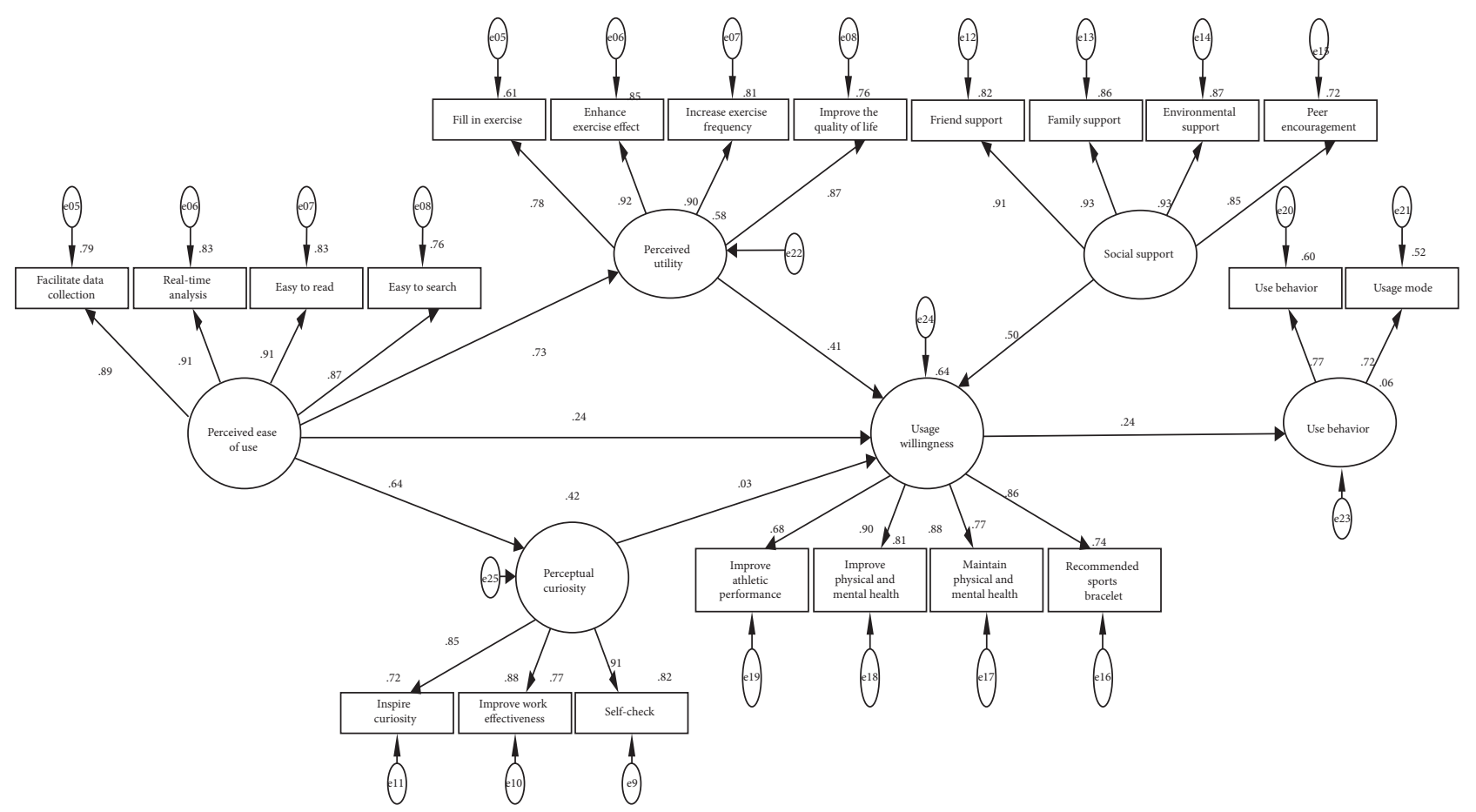

Figure 6: Models figure.

TABLE 11: Result of verification of the research design.

\begin{tabular}{|c|c|c|c|}
\hline Hypothesis & Path relationship & $\begin{array}{l}\text { Path } \\
\text { value }\end{array}$ & $\begin{array}{l}\text { Hypothesis } \\
\text { true/false }\end{array}$ \\
\hline 1 & $\begin{array}{l}\text { Perceived utility } \longrightarrow \\
\text { perceived utility }\end{array}$ & 0.73 & True \\
\hline 2 & $\begin{array}{l}\text { Perceived utility } \longrightarrow \\
\text { usage willingness }\end{array}$ & 0.24 & True \\
\hline 3 & $\begin{array}{l}\text { Perceived utility } \longrightarrow \\
\text { perceived curiosity }\end{array}$ & 0.64 & True \\
\hline 4 & $\begin{array}{l}\text { Perceived utility } \longrightarrow \\
\text { usage willingness }\end{array}$ & 0.41 & True \\
\hline 5 & $\begin{array}{c}\text { Perceived curiosity } \longrightarrow \\
\text { usage willingness }\end{array}$ & 0.03 & False \\
\hline 6 & $\begin{array}{c}\text { Social support } \longrightarrow \text { usage } \\
\text { willingness }\end{array}$ & 0.50 & True \\
\hline 7 & $\begin{array}{c}\text { Usage willingness } \longrightarrow \\
\text { usage behavior }\end{array}$ & 0.24 & True \\
\hline
\end{tabular}

easy-to-use device, it may possibly induce curiosity in users to further understand the real meanings behind the application of information and data collected through the sports wearable devices.

Hypothesis 4 is true in that there is a positive effect on usage intention by perceived utility of the users of sports wearable device (0.41). The research result is the same as that of Yuen [64]. The possible reason is that when the useful data and related information collected during each exercise process for users wearing the wearable device can enhance the result of the exercise or exercise habit, the willingness of wearing the sports wearable device will be elevated.
Hypothesis 5 of the research is false in that there is no positive effect on usage willingness by perceived curiosity of the wearable device users (0.03). The research result is not the same as that of Shiang et al. [63]. The possible reason may possibly be that when there is a need in the people for wearable devices, it means that there is usage willingness for the wearable devices, meaning that whether to use the wearable device will not be because of curiosity.

Hypothesis 6 is true in that there is a positive effect on usage willingness by social support (0.50). The research result is the same as that of Long [18]. The possible reason is that the important other parties around the user approving the result of using the wearable device will further motivate the user to continue using the wearable device.

Hypothesis 7 is true in that there is a positive effect on usage behavior by usage willingness (0.24). The research result is the same as that of Yi and Ren [64]. In other words, when the wearable device user is willing to use the equipment and also obtains the necessary information or training result, then the frequency or range of usage will relatively be increased.

\section{Future Research Recommendations}

5.1. On the Research Subjects. Because most of the wearable device users are joggers or triathlon enthusiasts, therefore, the research subjects in this study were mostly the above two sports enthusiasts. As for other popular sports participants in Taiwan such as hiking, mountain climbing, and bicycling, they are more lacking in the usage status and perception on wearable devices, especially in the mountain climbers who have higher demand for map and navigation on the wearable device than the joggers. Cyclists have higher demand in the 
frequency of pedaling, revolution count, and power output efficiency. Therefore, we recommend future studies to focus on hiking, mountain climbing, or cycling enthusiasts as research subjects to further collect more research data on wearable devices.

5.2. On the Scope of the Research. This research focuses on wearable device users as the main survey object. We recommend future studies to focus on large sports competition participants with questionnaire. After all, the participants in the large sports competitions are more rigorous in selftraining and will rely more on the wearable device data. Therefore, collecting data on the participants of large sports competitions will provide more real information on the usage status of the wearable devices.

5.3. On the Development of Wearable Devices. In the past, most wearable devices link with cell phones to transmit related sports data or fitness monitoring information. Cell phones have become a large central control platform. With the development of technology, sports wearable devices will march from cell phone-dependent devices toward fully independent devices that can conduct computations of calorie calculations, blood pressure, heart rate, step counter, altitude, air pressure, etc. Therefore, besides the battery power endurance of the wearable devices, the precision of the measurement must become even more precise, or the usage willingness in users of wearable device will be affected due to data lacking in precision. Future research studies can focus on the usage obstacle-related topics of wearable devices to make the research result even closer to the usage behavior of the wearable device users and further enhance the maturity of sports wearable devices.

\section{Data Availability}

No specific data were used to support this study.

\section{Conflicts of Interest}

The authors declare that there are no conflicts of interest regarding the publication of this paper.

\section{References}

[1] H. Y. Shuan, H. Shiao, T. C. Zuo, and F. S. Wei, "Industrial 4.0 communication technology and application," Journal of Industrial Mechatronics, vol. 413, pp. 17-29, 2017.

[2] C. H. Cheng, Management Information System, GOTOP, Taipei, Taiwan, 2017.

[3] M. Swan, "The quantified self: fundamental disruption in big data science and biological discovery," Big Data, vol. 1, no. 2, pp. 85-99, 2013.

[4] A. J. Bandodkar, I. Jeerapan, and J. Wang, "Wearable chemical sensors: present challenges and future prospects," ACS Sensors, vol. 1, no. 5, pp. 464-482, 2016.

[5] Gartner, "Gartner Says Global End-User Spending on Wearable Devices to Total \$52 Billion in 2020," 2019, https:// www.gartner.com/en/newsroom/press-releases/2019-10-30gartner-says-global-end-user-spending-on-wearable-dev.
[6] Science \& Technology Policy Research and Information Center, National Applied Research Laboratories, "The American $X$ generation using wearable devices is on the rise, know.stpi.narl.org.tw/Post/Read.aspx?PostID=15133, 2018.

[7] X. T. R. Kong, H. Luo, G. Q. Huang, and X. Yang, "Industrial wearable system: the human-centric empowering technology in Industry 4.0," Journal of Intelligent Manufacturing, vol. 30, no. 8, pp. 2853-2869, 2019.

[8] F. D. Davis, R. P. Bagozzi, and P. R. Warshaw, "User acceptance of computer technology: a comparison of two theoretical models," Management Science, vol. 35, no. 8, pp. 982-1003, 1989.

[9] F. D. Davis, "Perceived usefulness, perceived ease of use, and user acceptance of information technology," MIS Quarterly, vol. 13, no. 3, pp. 319-340, 1989.

[10] J. M. Peake, G. Kerr, and J. P. Sullivan, "A critical review of consumer wearables, mobile applications, and equipment for providing biofeedback, monitoring stress, and sleep in physically active populations," Frontiers in Physiology, vol. 9, p. 743, 2018.

[11] C. J. Yi and L. Luo, "Explore digital learning system usage attitude using technology acceptance model-with growth demand as the modulating variable," Journal of Information Management, vol. 21, no. 1, pp. 83-105, 2014.

[12] W. G. Shu and H. H. Jun, "The study on the factors impacting usage frequency of community to website platform in Taiwan: view point of technology acceptance model," Democracy and Governing, vol. 4, no. 2, pp. 1-38, 2017.

[13] C. J. Cheng, L. J. Liang, and Y. C. Fang, "Research on the impact on the convenience and curiosity of continued intention of learning English in the mobile learning environment," Journal of Educational Media and Library Science, vol. 48, no. 4, pp. 571-588, 2011.

[14] M. V. Voronina, Z. O. Tretyakova, E. G. Krivonozhkina, S. I. Buslaev, and G. G. Sidorenko, "Augmented reality in teaching descriptive geometry, engineering and computer graphics - systematic review and results of the Russian teachers' experience," EURASIA Journal of Mathematics, Science and Technology Education, vol. 15, no. 12, pp. 1-17, 2019.

[15] R. M. Yılmaz and Y. Göktaş, "Using augmented reality technology in education," Cukurova University Faculty of Education Journal, vol. 47, no. 2, pp. 510-537, 2018.

[16] C. B. Chi and S. S. Ling, "Analysis of influencing factors of consumers using innovative products-using electronic book reader as the example," Journal of National Kaohsiung University of Science and Technology, vol. 24, p. 191, 2010.

[17] R. M. Yilmaz, "Educational magic toys developed with augmented reality technology for early childhood education," Computers in Human Behavior, vol. 54, pp. 240-248, 2016.

[18] S. S. Long, Explore Employee EAP Usage Willingness and Behavior Using Technology Acceptance Model, Master's Thesis, Counseling and Applied Psychology Department, National Taichung University of Education, Taichung, Taiwan, 2017.

[19] H. Zhou and J. Chen, "Research on influencing factors of usage intension to use mobile intelligent wearable device," in Proceedings of the 8th International Conference on Management and Computer Science (ICMCS, Shenyang, China, August 2018.

[20] R. Estriegana, J.-A. Medina-Merodio, and R. Barchino, "Student acceptance of virtual laboratory and practical work: an extension of the technology acceptance model," Computers \& Education, vol. 135, pp. 1-14, 2019. 
[21] M. Arias-Oliva, J. Pelegrín-Borondo, and G. Matías-Clavero, "Variables influencing cryptocurrency use: a technology acceptance model in Spain," Frontiers in Psychology, vol. 10, p. 475, 2019.

[22] Y. Wang, S. Wang, J. Wang, J. Wei, and C. Wang, "An empirical study of consumers' intention to use ride-sharing services: using an extended technology acceptance model," Transportation, vol. 47, no. 1, pp. 397-415, 2020.

[23] L. Schmidthuber, D. Maresch, and M. Ginner, "Disruptive technologies and abundance in the service sector - toward a refined technology acceptance model," Technological Forecasting and Social Change, vol. 155, pp. 119-328, 2020.

[24] D. Cziráky, "Lisrel 8.54: a program for structural equation modelling with latent variables," Journal of Applied Econometrics, vol. 19, no. 1, pp. 135-141, 2004.

[25] Z. M. Zweber, "Organizational health climate: three facets and outcomes of relevance to organizations," Doctoral Dissertations, vol. 541, 2014.

[26] R. F. Devellis, Scale Development: Theory and Applications, Sage, Newbury Park, CA, 1991.

[27] K. T. Manis and D. Choi, "The virtual reality hardware acceptance model (VR-HAM): extending and individuating the technology acceptance model (TAM) for virtual reality hardware," Journal of Business Research, vol. 100, pp. 503-513, 2019.

[28] B. X. Qiu, Taijiang National Park 103 Annual Tourist Service Satisfaction Survey Project, Taijiang National Park, Tainan, Taiwan, 2014.

[29] C. Qian, Y. Zhang, C. Jiang, S. Pan, and Y. Rong, "A real-time data-driven collaborative mechanism in fixed-position assembly systems for smart manufacturing," Robotics and Computer-Integrated Manufacturing, vol. 61, Article ID 101841, 2020.

[30] L. K. Huei, "The crux and overcoming of the problem in the implementation of 'assistance plan of public agency employees,", Personnel Monthly, vol. 364, pp. 29-35, 2015.

[31] R. D. Lennox, D. Sharar, E. Schmitz, and D. B. Goehner, "Development and validation of the chestnut global partners workplace outcome suite," Journal of Workplace Behavioral Health, vol. 25, no. 2, pp. 107-131, 2010.

[32] K. J. Ming and C. M. Ren, "Research on using cloud storage using integrated technology acceptance model - using Dropbox as the example," Journal of Information Management, vol. 7, no. 2, pp. 50-69, 2014.

[33] R. P. Bagozzi and Y. Yi, "On the evaluation of structural equation models," Journal of the Academy of Marketing Science, vol. 16, no. 1, pp. 74-94, 1988.

[34] J. F. Hair, R. L. Anderson, and W. C. Tatham, Multivariate Data Analysis with Reading, Biostat, Englewood, NJ, 1998.

[35] C. S. Yu, Structural Equation Model, Psychology Publishing, Taipei, Taiwan, 2007.

[36] H. Qiu, Structural Equation Model: LISREL's Theory, Technology and Application, Futaba, Taipei, Taiwan, 2003.

[37] W. Zhang, "SEM paper writing does not ask for help. Taipei City: Dingmao.Hair," in Taipei City: Dingmao.Hair, J. F., R. E. Anderson, R. L. Tatham, and W. C. Black, Eds., PrenticeHall, Upper saddle River, NJ, 7 edition, 2011.

[38] C. Fornell and D. F. Larcker, "Structural equation models with unobservable variables and measurement error: algebra and Statistics," Journal of Marketing Research, vol. 18, no. 3, pp. 382-388, 1981.

[39] M. Wu, Structural Equation Model Method and Practical Application, Li Wen, Kaohsiung City, 2009.
[40] W. M. Long, Structural Equation Modeling-Method and Practical Application, Liwen Publishing, Kaohsiung, Taiwan, 2009.

[41] G. Torkzadeh, X. Koufteros, and K. Pflughoeft, "Confirmatory analysis of computer self-efficacy," Structural Equation Modeling: A Multidisciplinary Journal, vol. 10, no. 2, pp. 263-275, 2003.

[42] C. W. Hau, SEM Thesis Writing Independently, Tutor Tristar, Kaohsiung, Taiwan, 2011.

[43] H. M. Cho, P. F. Chuan, and H. C. Aei, "Research on the behavior of water sports tourists-verification of theory planned behaviour," Journal of Taiwan Society for Sport Management, vol. 11, no. 2, pp. 85-107, 2011.

[44] M. Xu, "A study on the validation of the construct validity of the sports tourism obstacle scale for college students," Journal of Sports and Leisure Management, vol. 7, no. 1, pp. 174-186, 2010.

[45] B. Lin, T. Liu, and M. Xu, "Validation of the satisfaction model of large-scale sports games-based on the 2009 kaohsiung world games," Leisure Industry Management Journal, vol. 3, no. 3, pp. 58-73, 2010.

[46] P. M. Bentler, "On the fit of models to covariances and methodology to the Bulletin," Psychological Bulletin, vol. 112, no. 3, pp. 400-404, 1992.

[47] J. F. Hair, R. E. Anderson, R. L. Tatham, and W. C. Black, Multivariate Data Analysis, Prentice-Hall, Upper saddle River, NJ, 5 edition, 1998.

[48] M. W. Browne and R. Cudeck, "Alternative ways of assessing model fit," in Testing Structural Equation Models, K. A. Bollen and J. S. Long, Eds., pp. 445-455, Sage, Newbury Park, CA, 1993.

[49] M. W. Browne and G. Arminger, "Specification and estimation of mean- and covariance-structure models," in Handbook of Statistical Modeling for the Social and Behavioral Sciences, G. Arminger, C. C. Clogg, and M. E. Sobel, Eds., pp. 185-249, Plenum Press, New York, 1995.

[50] R. P. Bagozzi and Y. Yi, "On the evaluation for structural equation models," Journal of the Academy of Marketing Science, vol. 16, pp. 74-94, 1988.

[51] M. W. Browne and R. Cudeck, "Alternative ways of assessing model fit," in Testing Structural Equation Models, K. A. Bollen and J. S. Long, Eds., pp. 136-162, Sage, Newbury Park, CA, 1993.

[52] H. W. Marsh and J. Balla, "Goodness of fit in confirmatory factor analysis: the effects of sample size and model parsimony," Quality \& Quantity, vol. 28, no. 2, pp. 185-217, 1994.

[53] J. H. Steiger, "Structural model evaluation and modification: an interval estimation approach," Multivariate Behavioral Research, vol. 25, no. 2, pp. 173-180, 1990.

[54] H. M. Sugawara and R. C. MaCallum, "Effect of estimation method on incremental fit indexes for covariance structure models," Applied Psychological Measurement, vol. 17, pp. 365-377, 1983.

[55] M. W. Browne and G. Mels, Ramona User's Guide, Department of Psychology, Ohio State University, Columbus, Ohio, 1990.

[56] R. P. McDonald and M.-H. R. Ho, "Principles and practice in reporting structural equation analyses," Psychological Methods, vol. 7, no. 1, pp. 64-82, 2002.

[57] R. E. Schumacker and R. G. Lomax, A Beginner's Guide to Structural Equation Modeling, Lawrence Erlbaum Associates, Mahwah, NJ, 2 edition, 2004.

[58] J. H. Steiger, Ezpath: A Supplementary Module for Systat and Sysgraph, SYSTAT, Evanston, IL, 1989. 
[59] L. t. Hu and P. M. Bentler, "Cutoff criteria for fit indexes in covariance structure analysis: conventional criteria versus new alternatives," Structural Equation Modeling: A Multidisciplinary Journal, vol. 6, no. 1, pp. 1-55, 1999.

[60] F. Huang, Structural Equation Model Theory and Application, Wunan, Taipei, Taiwan, fifth edition, 2007.

[61] X. Fan, B. Thompson, and L. Wang, "Effects of sample size, estimation methods, and model specification on structural equation modeling fit indexes," Structural Equation Modeling: A Multidisciplinary Journal, vol. 6, no. 1, pp. 56-83, 1999.

[62] K. Y. Yuen, Using Technology Acceptance Model to Explore the Factors that Influence Consumer Intention in Using Smart Electric Automobiles, Engineering Management Graduate Program, National Cheng Kung University, Tainan, Taiwan, 2011.

[63] L. L. Shiang, C. C. Yuan, P. J. Chi, P. C. Yu, and W. S. Ting, "Exploring the key factors in the purchase willingness on hot Korean merchandise," Journal of Innovation and Business Management, vol. 6, no. 2, pp. 1-18, 2015.

[64] L. J. Yi and K. H. Ren, "Study on the acceptance level and usage behavior of electronic resources integration inquiry system," Journal of Educational Media and Library Science, vol. 49, no. 3, pp. 30-62, 2012. 